\title{
O sistema nacional de avaliação: características, dispositivos legais e resultados
}

ISABELLE FIORELLI SILVA*

\section{RESUMO}

No presente trabalho, objetiva-se, num primeiro momento, compreender e apresentar as características e peculiaridades do sistema de avaliação nacional brasileiro. Num segundo momento, a finalidade é refletir acerca da funcionalidade do sistema e de seus dispositivos legais e técnicos na busca pela mensuração da qualidade do ensino no país. E, num terceiro momento, serão apresentados dados do Saeb, de taxas de aprovação e do Ideb para tecermos algumas reflexōes, ainda que preliminares, acerca de seus resultados em 2005 e 2007. Percebese a construçáo de um sistema avaliativo complexo com informaçóes relevantes a respeito do desempenho estudantil e do contexto intra e extraescolares. Entretanto, deve haver parcimônia na utilização de seus resultados, pois podemos utilizá-los tanto como norteadores no aprimoramento das políticas educacionais rumo à universalização da qualidade do ensino como incorrer numa simplificação do significado da qualidade de ensino, vertendo para uma lógica meritocrática e, consequentemente, competitiva entre as unidades e redes de ensino.

Palavras-chave: Saeb, Mensuração, Qualidade do ensino, Políticas educacionais.

\section{RESUMEN}

El presente trabajo, tiene como objetivo, en primer lugar, comprender y presentar las características y peculiaridades del sistema de evaluación nacional brasileño y en segundo lugar, reflexionar acerca de la funcionalidad del sistema y de sus dispositivos legales y técnicos

* Professora do Departamento de Educação - área de política e gestáo da educação - da Universidade Estadual de Londrina (UEL) (fiorelli@uel.br). 
para intentar medir la calidad de la enseñanza en el país. Por último, se presentan datos del Sistema de Evaluación de la Educación Básica (Saeb), de las tasas de aprobación y del Ideb para realizar algunas reflexiones preliminares sobre los resultados obtenidos en $2005 \mathrm{y}$ 2007. Se percibe la construcción de un sistema complejo de evaluación con informaciones relevantes sobre el desempeño estudiantil y el contexto intra y extraescolar. Sin embargo, debe tomarse con cautela la aplicación de los resultados, ya que pueden ser utilizados tanto como orientadores en el perfeccionamiento de las políticas educativas rumbo a la universalización de la calidad de la enseñanza, como en una simplificación del significado de la calidad de enseńanza, conduciéndonos a una lógica meritocrática y, consecuentemente, competitiva entre las unidades y las redes de enseńanza.

Palabras clave: Saeb, Medición, Calidad de la enseñanza, Políticas educativas.

\section{ABSTRACT}

This paper initially aims to understand and to present the characteristics and peculiarities of Brazil's national evaluation system. Next, the objective is to reflect about the functionality of the system and its legal and technical provisions to measure the teaching quality in the country. Finally, it will present data from Saeb (Basic Education Evaluation System), rates of student approval, and from Ideb (Index of Basic Education Development) to offer some reflections, though preliminary, about their results in 2005 and 2007. One is able to notice the construction of a complex evaluation system with important information about student performance and intra and extra-school context. However, these results must be used with care, because we can use them to guide the improvement of educational policies towards the universalization of teaching quality, but also to incur a simplification of the meaning of teaching quality, drifting towards a meritocratic and, consequently, competitive logic between the units and the teaching networks.

Keywords: National evaluation system, Evaluation, Teaching quality, Educational policies. 
O sistema de avaliação brasileiro foi se ampliando e se complexificando desde o fim da década de 1980 até o atual contexto. Segundo Bonamino e Franco (1999), em 1988 o entáo criado Sistema Nacional de Avaliaçâo do Ensino Público de $1^{\circ}$ Grau (Saep/MEC) realiza uma aplicaçāo piloto nos Estados do Paraná e Rio Grande do Norte, com a intençáo de testar instrumentos e procedimentos. Entretanto, a falta de recursos impediu o prosseguimento do projeto, deslanchando efetivamente a partir de 1990, com a viabilização do primeiro ciclo do Sistema Nacional de Avaliaçáo da Educação Básica (Saeb). Na sequência, os ciclos de avaliação se davam por amostragem, trianualmente. A partir de 2001, ocorre uma mobilização do MEC no sentido de empreender um rigoroso planejamento no funcionamento do Saeb, sendo repaginado e aprimorado. Em 2005, é novamente aperfeiçoado, ampliandose com a inclusão da Prova Brasil, tendo, entre outras mudanças, uma avaliação em larga escala de caráter universal com aplicação bianual.

Atualmente, todas as etapas e níveis de ensino, exceto a educaçáo infantil, sofrem avaliaçáo padronizada, organizada e centralizada pelo Instituto Nacional de Estudos e Pesquisas Educacionais Anísio Teixeira (Inep) órgáo ligado ao Ministério da Educação e Cultura (MEC). O destaque premente nos resultados do Sistema Nacional de Avaliação da Educaçáo Básica (Saeb) é do Índice de Desenvolvimento da Educaçáo Básica (Ideb) que, por meio de acordos e convênios intergovernamentais, têm instigado a curiosidade de pesquisadores da área acerca do seu funcionamento, mecanismos, relevância e implicaçōes na política educacional brasileira.

$\mathrm{O}$ acordo mais incisivo hoje na política educacional brasileira, exponencialmente seu sistema de avaliação, é o Compromisso Todos pela Educação, organização composta por empresas, com atuaçáo predominante no setor financeiro nacional e internacional. São elas: grupo Gerdau, grupo Suzano, Banco Itaú, Banco Bradesco, organizaçóes Globo, entre outras. Em articulação com órgãos públicos e/ou representativos das gestôes educacionais centrais e locais, tal organização construiu um plano de metas para a política educacional brasileira, entre elas a criação do Ideb, e conquistaram a aprovação do Decreto-Lei n. 6.094, de abril de 2007 que

dispóe sobre a implementaçăo do Plano de Metas Compromisso Todos pela Educaçâo, pela Uniáo Federal, em regime de colaboraçâo com Municípios, Distrito Federal e Estados, e a participação das famílias e da comunidade, mediante programas e açôes de assistência técnica e financeira, visando a mobilização social pela melhoria da qualidade da educação básica. (Brasil, 2007) 
Outra organização que tem ganho terreno em parcerias com mais de 500 gestôes municipais de educação do país é o Instituto Ayrton Senna com seus programas: Gestão nota 10, Acelera Brasil, Se liga, Educação pelo esporte, Superação jovem, Escola conectada, Circuito campeáo e Comunidade conectada.

Com isso, trata-se de buscar o entendimento acerca das principais características do sistema de avaliaçáo brasileiro, destacando sua estrutura e mecanismos de gestão na qual se consubstancia o referido sistema. Embasados nessa compreensáo, procurou-se analisar os dispositivos legais que o sustentam, ressaltando os principais pesquisadores da área com suas reflexóes imersas em produçóes atuais sobre a temática em questão; apresentar análise preliminar dos dados do Saeb, de taxas de aprovaçăo e do Ideb de 2005 e 2007; e, por fim, buscar estabelecer relaçóes entre os objetivos e metas proclamadas no cenário político-legal, assim como aferir os resultados produzidos pelo sistema de avaliação nacional brasileiro.

\section{PRINCIPAIS CARACTERÍSTICAS DO SAEB}

Normatizado pela Portaria n. 931, de março de 2005, o Saeb é composto pela Avaliação Nacional da Educaçáo Básica (Aneb) e pela Prova Brasil, sendo, a última, composta pela Avaliação Nacional do Rendimento Escolar (Anresc). A última etapa da educaçáo básica é avaliada por meio do Exame Nacional do Ensino Médio (Enem). O ensino superior é avaliado pelo Sistema Nacional de Avaliação da Educação Superior (Sinaes) por meio, dentre outros instrumentos, do Exame Nacional de Desempenho dos Estudantes (Enade). Entretanto, o cerne deste estudo se propóe a apresentar e analisar o sistema de avaliação brasileiro voltado para a educação básica.

A avaliaçáo da educação básica é concebida, aplicada e organizada pelo Inep, com periodicidade bianual, medindo o desempenho em língua portuguesa e matemática nos últimos anos de cada etapa da educaçáo básica. Cabe assinalar que o Instituto náo realiza todo o processo sozinho, pois recebe assessoria de empresa especializada na constituiçáo de base de dados e na produção das escalas de proficiência, que é contratada por meio de licitaçáo internacional.

A prova do Saeb (Aneb) possui abrangência amostral. Segundo o MEC/Inep, alguns alunos são selecionados estatisticamente de $4^{\mathrm{a}}$ e de $8^{\mathrm{a}}$ série do ensino fundamental, das redes particulares e rural, e de $3^{\circ}$ ano do ensino médio, das redes pública e particular, de área urbana. Passou por vários ciclos desde 1990; inicialmente era aplicada trianualmente, e a partir de 2003 sua aplicabilidade passa a ser bianual. 
A Prova Brasil (Anresc) - iniciada em 2005 - é censitária e aplicada bianualmente na zona urbana e rural de escolas públicas para alunos matriculados na $4^{\mathrm{a}} \mathrm{e}$ $8^{a}$ séries do ensino fundamental. Oferece dados a cada unidade da Federação, aos municípios e escolas participantes. A Prova Brasil avalia quase todos os estudantes da rede pública urbana de ensino, de $4^{\mathrm{a}}$ e $8^{\mathrm{a}}$ séries do ensino fundamental, exceto escolas com menos de 20 alunos matriculados nas séries avaliadas. De acordo com o MEC, em 2009, as escolas rurais de ensino fundamental com mais de 20 alunos nas séries avaliadas também fizeram a Prova Brasil.

O quadro 1 apresenta as principais semelhanças e diferenças entre o Saeb e a Prova Brasil'.

Quadro 1 - Semelhanças e diferenças entre a Prova Brasil e o Saeb

\begin{tabular}{|l|l|}
\hline \multicolumn{1}{|c|}{ Prova Brasil } & \multicolumn{1}{|c|}{ Saeb } \\
\hline Foi criada em 2005. & A primeira aplicação ocorreu em 1990. \\
\hline $\begin{array}{l}\text { Alunos fazem prova de Língua Portuguesa e } \\
\text { Matemática. }\end{array}$ & $\begin{array}{l}\text { Alunos fazem prova de Língua Portuguesa e } \\
\text { Matemática. }\end{array}$ \\
\hline $\begin{array}{l}\text { Avalia apenas estudantes de ensino } \\
\text { fundamental, de } 4^{a} \text { e } 8^{a} \text { séries. }\end{array}$ & $\begin{array}{l}\text { Avalia estudantes de } 4^{a} \text { e 8a séries do ensino } \\
\text { fundamental e estudantes do 30 ano do } \\
\text { ensino médio. }\end{array}$ \\
\hline $\begin{array}{l}\text { Avalia as escolas públicas localizadas em } \\
\text { área urbana. }\end{array}$ & $\begin{array}{l}\text { Avalia alunos da rede pública e da rede } \\
\text { privada, de escolas localizadas nas áreas } \\
\text { urbana e rural. }\end{array}$ \\
\hline $\begin{array}{l}\text { A avaliação é quase universal: todos os } \\
\text { estudantes das séries avaliadas, de todas as } \\
\text { escolas públicas urbanas do Brasil com mais } \\
\text { de 20 alunos na série, realizam a prova. }\end{array}$ & $\begin{array}{l}\text { A avaliação é amostral, ou seja, parte dos } \\
\text { estudantes brasileiros das séries avaliadas } \\
\text { participam da prova. }\end{array}$ \\
\hline $\begin{array}{l}\text { Fornece as médias de desempenho para o o } \\
\text { Brasil, regiões e unidades da Federação, } \\
\text { para cada um dos municípios e escolas } \\
\text { participantes. }\end{array}$ & $\begin{array}{l}\text { Oferece resultados de desempenho apenas } \\
\text { para o Brasil, regiões e unidades da } \\
\text { Federação. }\end{array}$ \\
\hline
\end{tabular}

Fonte: Brasil, 2009.

Com base em informaçóes do Inep, a metodologia das duas avaliaçōes é a mesma, contudo, passaram a ser operacionalizadas em conjunto, desde 2007. Afirma ainda que como são avaliaçóes complementares, uma não implica a extinção da outra.

${ }^{1}$ Consulte o site <www.provabrasil.inep.gov.br $>$. 
Além das provas de desempenho, sáo aplicados questionários contextuais aos alunos, professores e diretores das escolas avaliadas, com o intuito de identificar o nível socioeconômico dos alunos, hábitos de estudo, perfil e condiçóes de trabalho dos docentes e diretores, tipo e organização da escola, projeto pedagógico, insumos e instalaçóes.

Iza Locatelli (2002) fez uma apresentação detalhada da estruturação do Saeb a partir de 2001 e nos elucida acerca dos constructos dos questionários contextuais:

No constructo relacionado aos alunos foram privilegiados a caracterizaçáo sociodemográfica, o capital cultural, o capital social, a motivação e autoestima, as práticas de estudos e a trajetória escolar. (...) Optou-se por considerar a caracterização sociodemográfica dos professores, a formaçáo, a experiência profissional, as condiçôes de trabalho, o estilo pedagógico e a expectativa destes em relação aos alunos. Quanto à escola, os constructos foram captados pelos questionários do diretor, da escola e do professor. Aborda-se, nesses, a caracterização sociodemográfica do diretor, formação, experiência, liderança, condiçōes de trabalho do diretor e equipe, trabalho colaborativo, organização do ensino e políticas de promoção, clima acadêmico, clima disciplinar, recursos pedagógicos, situaçáo das instalaçóes e equipamentos e atividades extracurriculares. (p. 11)

De acordo com a autora, o Ministério da Educação (MEC) organizou em 2001, para definição dessas e de outras questóes pertinentes ao sistema, uma equipe responsável pela reediçáo do Saeb, a qual promoveu vários encontros, reuniōes e seminários. Descreve que foram definidos os passos utilizados para tal construção, dentre eles a elaboraçáo do modelo de prova e a seleçâo das prioridades definidas para cada uma das séries a serem avaliadas.

Além disso, segundo a autora, naquele contexto houve a discussáo em torno da estruturaçáo dos questionários contextuais, da construção do plano amostral, da constituição da base de dados, do uso da teoria da resposta ao item (TRI) na organização de escalas de proficiência, na equalização das provas e na calibraçáo de itens e nas formas de apresentaçáo e disseminação dos resultados (Locatelli, 2002, p. 7).

Naquele contexto, também foram elaboradas as matrizes de referência que compóem a base de dados do Saeb, especificando conteúdos, competências e habilidades das séries a serem avaliadas. Elas foram revisadas por especialistas e validadas pelas secretarias de educaçáo de todos os Estados brasileiros. Paralelamente a isso, especialistas na área de estatística se debruçaram na dimensão metodológica de coleta $\mathrm{e}$ armazenamento dos dados coletados. Nota-se, desde então, a crescente participaçáo 
de economistas e estatísticos na composição e manutenção do sistema de avaliação da educação brasileiro.

Tal encaminhamento deflagra parte significativa do processo de complexificaçáo do sistema avaliativo no seu processo de constituição, chegando ao que é hoje no país. Muito do que se definiu por essa equipe fez-se presente nas ediçóes posteriores do Saeb e em sua última regulamentação oficial.

Percebe-se a construção de um sistema avaliativo complexo, com informaçâes relevantes acerca do desempenho estudantil e do contexto intra e extraescolares. Entretanto, deve haver parcimônia na utilização de seus resultados, uma vez que podemos utilizá-los, tanto como norteador no aprimoramento das políticas educacionais rumo à universalização da qualidade do ensino enquanto direito subjetivo dos cidadãos como incorrer numa simplificação do significado de qualidade de ensino, vertendo para uma lógica meritocrática, eficienticista e, consequentemente, competitiva entre as unidades e redes de ensino.

Outro perigo apontado por Juan Casassus (2009) é a possibilidade da redução dos currículos às áreas e tópicos abrangidos pela avaliação padronizada, pois os professores podem acabar "ensinando para o exame", fazendo com que "os professores ocupem o tempo a exercitar os alunos a escolher uma resposta entre as apresentadas" (p. 75).

O autor, que analisa a implantação dos sistemas de avaliação centralizados na América Latina, faz sérias críticas às avaliaçóes padronizadas, denominadas por ele de provas estandartizadas de medição, afirmando que estas possuem consequências sociais, quando aumentam a desigualdade entre as escolas mais carentes daquelas mais abastadas.

Os resultados das provas indicam-nos que no extremo dos "burros" e das baixas pontuaçōes se encontram os pobres, e que os ricos se encontram no extremo dos "inteligentes" e com pontuaçóes altas. (...) Um sistema meritocrático numa democracia formal, ou seja, uma democracia que não toma em consideração a desigualdade de condiçōes e os contextos de pobreza, que nos diz que há uma razão de ser para os burros serem pobres: é porque são burros. Assumir isto é esquecer um ponto crucial: os efeitos negativos que a pobreza tem na aprendizagem e no desenvolvimento cognitivo dos alunos. (p. 76)

Podemos endossar a afirmaçáo de Casassus, apresentando pesquisas realizadas com base na realidade brasileira. Estudos exploratórios dos dados do Saeb de 2005 destacam a relevância de pesquisadores e geradores de políticas da área se deterem na investigação e compreensão da qualidade do ensino, pautados na combinação de 
vários determinantes ${ }^{2}$, para náo se visualizar o resultado do desempenho dos alunos isolada e/ou alienadamente, o que pode redundar na responsabilizaçáo individual dos alunos, dos professores e das escolas pelo seu baixo ou alto desempenho.

Por exemplo, Alves, Passador e Noronha (2007), em pesquisa realizada na rede estadual da educaçáo básica de Goiás, com base em dados do Censo Escolar e da Prova Brasil, combinam três fatores: 1) a origem socioeconômica do aluno, 2) as condiçóes de oferta de ensino e 3) os indicadores de resultado/desempenho da escola. Os resultados de suas análises evidenciam que os alunos de baixo desempenho têm condiçōes mais desfavoráveis e que "alunos com origem socioeconômica favorável, em escolas com boa infraestrutura e com professores qualificados conseguem bons desempenhos" (p. 14).

Soares e Andrade (2006), em pesquisa que objetivava medir o nível socioeconômico dos alunos das escolas de Belo Horizonte, destacam a relevância desse fator na percepçáo da equidade e qualidade do ensino. Eles apontam estudo importante, como o "Relatório Coleman" (1966), que indica que os fatores extraescolares são os mais importantes para a explicação dos resultados escolares. Entretanto, os autores alertam que as melhores análises na área incorporam vários fatores, ao invés de se apoiar em apenas um determinante no desempenho estudantil: "ou seja, nem os fatores extraescolares conseguem sozinhos explicar o desempenho cognitivo, nem a escola faz toda a diferença como querem fazer crer determinadas campanhas publicitárias de escolas particulares" (p. 109).

Não podemos deixar de considerar que o nível socioeconômico pode ser um fator preponderante no desempenho dos alunos, mas temos que considerá-lo em estreita relação com outros fatores que interferem direta e indiretamente nos resultados escolares.

Apesar de o nível socioeconômico ser um determinante presente no questionário de contexto aplicado no Saeb, ele não é considerado a contento na constituiçáo, divulgação e exploração dos indicadores de qualidade de ensino produzidos pelo governo e nem considerado seriamente na agenda de redefinição de políticas públicas, como, por exemplo, no Plano de Açóes Articuladas ( $\mathrm{PAR}^{3}$ ), proposto pelo MEC

${ }^{2}$ Nível socioeconômico e cultural dos alunos, formaçáo docente, valorizaçáo do magistério, condiçôes materiais e imateriais de trabalho, infraestrutura, insumos e instalaçốes.

${ }^{3}$ A partir do lançamento do Plano de Desenvolvimento da Educação (PDE), em 2007, todas as transferências voluntárias e assistência técnica do MEC aos municípios, Estados e Distrito Federal estão vinculadas à adesão ao Plano de Metas Compromisso Todos pela Educação e à elaboração do Plano de Açóes Articuladas (PAR). Atualmente, todos os 26 Estados, o Distrito Federal e os 5.563 municípios assinaram o Termo de Adesão ao Plano de Metas do PDE. 
por meio de convênios com os entes federados, previsto no Decreto-Lei n. 6.094, de 24 de abril de 2007. O que se percebe é que as notas referentes ao desempenho estudantil são supervalorizadas e destacadas enfaticamente em detrimento de outros determinantes de igual ou maior relevância na mensuraçâo da qualidade do ensino.

Tal evidência vem confirmar a premissa de que o sistema de avaliação brasileiro, apesar da nítida evoluçáo desde sua criação, carece de amplo debate para desvelar alguns impasses e generalizações que se encontram presentes nos resultados do Saeb e do Ideb disseminados pelo Inep. Como, por exemplo, precisa explorar e utilizar os dados coletados nos questionários contextuais na mensuração da qualidade do ensino no Brasil.

\section{DISPOSITIVOS LEGAIS QUE SUSTENTAM O SAEB}

$\mathrm{Na}$ portaria de 2005 que normatiza o Saeb, em seu parágrafo $2^{\circ}$, estão explicitados os seguintes objetivos gerais:

(...) a) avaliar a qualidade do ensino ministrado nas escolas, de forma que cada unidade escolar receba o resultado global; b) contribuir para o desenvolvimento, em todos os níveis educativos, de uma cultura avaliativa que estimule a melhoria dos padrôes de qualidade e equidade da educaçáo brasileira e adequados controles sociais de seus resultados; c) concorrer para a melhoria da qualidade de ensino, redução das desigualdades e a democratizaçáo da gestáo do ensino público nos estabelecimentos oficiais, em consonância com as metas e políticas estabelecidas pelas diretrizes da educação nacional; d) oportunizar informações sistemáticas sobre as unidades escolares. Tais informaçôes serão úteis para a escolha dos gestores da rede à qual pertençam. (Brasil, 2005, grifos nossos)

Analisando tanto o documento que regulamenta o Saeb (Brasil, 2005) quanto o que regulamenta o Plano de Metas Compromisso Todos pela Educação ${ }^{4}$ (Brasil, 2007) podemos identificar seu nítido norteamento pela descentralizaçáo administrativa e financeira, quando: 1) celebra convênio que induz cada ente federado a resolver seus problemas nas suas redes de ensino, por meio da elaboraçáo do PAR, o que pode gerar uma diferenciação entre os sistemas, em vez da equidade procla-

\footnotetext{
${ }^{4}$ Decreto n. 6.094, de 24 de abril de 2007. "Dispóe sobre a implementaçăo do Plano de Metas Compromisso Todos pela Educação, pela União Federal, em regime de colaboraçâo com Municípios, Distrito Federal e Estados, e a participação das famílias e da comunidade, mediante programas e açóes de assistência técnica e financeira, visando a mobilização social pela melhoria da qualidade da educação básica" (Brasil, 2007).
} 
mada no documento; 2) reproduz objetivos já expressos na legislaçáo educacional brasileira (LDB, PNE, Fundeb5), como, por exemplo, o estabelecimento de um padrão mínimo de qualidade, que carece urgentemente de discussão em torno de sua significância e estratégias claras para a superação de seu caráter polissêmico.

Por exemplo, qual o entendimento que se tem e como obter a melhoria do padrão de qualidade do ensino? A democratização da gestão está pautada em qual grau e instância de participaçáo e quais seus pressupostos subjacentes? Quais as estratégias mais eficazes para a busca da equidade, desconsiderando seu viés meritocrático que justifica as diferenças?

Tais dilemas estão presentes nas críticas de pesquisadores da área; entretanto, ainda estáo longe de ser superados. Pelo contrário, cada vez mais se evidencia que o curso em movimento, desde os anos de 1990, vem sendo reforçado, ao invés de modificado, para superarmos esses dilemas destacados em pesquisas consistentes.

Araújo e Fernandes (2009) apresentaram estudo sobre a qualidade do ensino e a avaliação em larga escala no Brasil. Para as autoras, o conjunto de ações desencadeadas para aferir a qualidade do ensino no Brasil “(...) ressignificaram o papel da racionalidade técnica, aplicando-a de modo decisivo no âmbito da política de financiamento do ensino fundamental e estimulando sua relevância no âmbito de outros aspectos da política educacional" (p. 1001).

A racionalidade técnica vem sendo aplicada na política educacional brasileira, desde o período da ditadura militar, e vem se adaptando a cada contexto político-econômico, estabelecendo novas estratégias de açáo. Entre elas, a atençấo aos resultados, recomendada pelo Banco Mundial (BM), recebe destaque e a qualidade do ensino é aferida mediante a combinaçáo dos resultados cognitivos (desempenho) com os de fluxo (aprovação, reprovação, evasão) no ínterim da política educacional brasileira. Ela está associada a um modelo de gestáo consubstanciado em parcerias, tanto no plano intergovernamental quanto na intersecçáo entre o setor público e o privado, como nos casos de parceria entre o Instituto Ayrton Senna e as secretarias municipais de educação do país afora.

Confirma-se, cada vez mais, que nosso sistema de avaliação está centrado na aferição da qualidade, pautada na racionalidade técnica, quando analisamos o me-

${ }^{5}$ Lei de Diretrizes e Bases da Educação Nacional n. 9.394, de 20 de dezembro de 1996; Plano Nacional de Educaçáo - Lei n. 10.172, de 9 de janeiro de 2001; e Lei n. 11.494, de 20 de junho de 2007, que regulamenta o Fundo de Manutençāo e Desenvolvimento da Educaçáo Básica e de Valorizaçáo do Magistério. 
canismo do Índice de Desenvolvimento da Educação Básica (Ideb). Ele foi criado em 2007 para medir o desenvolvimento da educação básica no Brasil. Sua legitimação ocorreu no Decreto n. 6.094, de 24 de abril de 2007, no qual foi regulamentado o Plano de Metas Compromisso Todos pela Educação. No capítulo II, artigo 3, evidencia-se sua criaçáo.

A qualidade da educação básica será aferida, objetivamente, com base no Ideb, calculado e divulgado periodicamente pelo Inep, a partir de dados sobre rendimento escolar, combinados com o desempenho dos alunos, constantes do censo escolar e do Sistema de Avaliação da Educação Básica - Saeb, composto pela Avaliação Nacional da Educação Básica - Aneb e a Avaliação Nacional de Rendimento Escolar (Prova Brasil). (Brasil, 2007)

No decreto em questáo está deflagrado o estabelecimento de parceria entre o MEC e os entes federados, por meio de celebraçáo de termos de compromisso e convênio para assistência técnica e financeira, confirmando-se, mais uma vez, a tendência de racionalidade técnica e de descentralização no eixo de definição da política educacional do país.

O índice foi lançado no bojo do Plano de Desenvolvimento da Educação (PDE), nesse mesmo contexto, pelo Ministro da Educação Fernando Haddad. O plano foi gestado pelo movimento Compromisso Todos pela Educação, que reuniu setores da sociedade civil e foi normatizado pelo MEC pelo decreto citado anteriormente.

O indicador é calculado com base no desempenho do estudante nas avaliaçōes padronizadas e em taxas de aprovaçáo, pautado nos resultados da Prova Brasil e do Censo Escolar. "Assim, para que o Ideb de uma escola ou rede cresça é preciso que o aluno aprenda, não repita o ano e frequente a sala de aula" (Brasil, 2007).

Há que se considerar plausível a combinaçáo do indicador de fluxo com o de desempenho, tentando combinar aspecto quantitativo com qualitativo, pois, historicamente, a política educacional brasileira, ora enfatizou um, ora enfatizou outro aspecto. Com isso, tal índice pode nos indicar algumas premissas, acerca das nuances necessárias para a busca da melhoria da qualidade do ensino e, consequentemente, para o alcance da meta de se chegar à média 6 até 2022 no País. Por isso, seus resultados devem ser cada vez mais explorados por pesquisadores da área, para relacioná-los e compará-los com outros indicadores ainda não enfatizados pelo sistema, além de destacar seus limites e possibilidades.

Entretanto, torna-se eminente a preocupaçáo com o uso que se faz dos resultados obtidos no Ideb, pois, dependendo das estratégias utilizadas mediante tais 
resultados, pode-se incorrer numa camuflada indução para que as escolas evitem a reprovaçáo dos estudantes, mesmo que eles náo atinjam um nível de aprendizagem suficiente para aprovação. Como o próprio presidente do Inep, Reynaldo Fernandes (2007), afirma, "o fato é que não se pode descartar a possibilidade de as escolas e/ou redes de ensino adotarem medidas que melhorem o fluxo e piorem o desempenho nos exames padronizados e vice-versa" (p. 8).

O autor pontua, em texto elucidativo sobre o Ideb, que dados de proficiência e dados de fluxo não são independentes entre si, pois a melhora/piora de um pode indicar a melhora/piora do outro (Fernandes, 2007). Por exemplo, uma unidade escolar pode adotar medidas para reduzir a reprovação, mas se tais medidas náo garantirem o aprendizado mínimo dos conteúdos referentes à série, isso implicará redução do desempenho nos exames padronizados e vice-versa.

Quando afirmamos que o sistema brasileiro de avaliaçáo da educaçáo, e com ele o Saeb e Ideb, carecem de amplo debate para a superaçáo de impasses e generalizaçóes ainda presentes, destacamos o limite de considerar apenas dois fatores - resultados de desempenho e taxas de aprovação - que, de certa forma, mensuram a qualidade do ensino no Brasil. O que acaba por desconsiderar outros fatores de igual ou maior relevância na medição da qualidade do ensino, tais como: nível socioeconômico e cultural dos alunos, formação docente, valorização do magistério, condições materiais e imateriais de trabalho, gestão escolar, infraestrutura da escola, insumos, entre outros.

Sofremos ainda avaliaçáo internacional realizada pela Organizaçáo para a Cooperaçáo e o Desenvolvimento Econômico (OCDE): o Programa Internacional de Avaliação de Alunos (PISA) é um exame realizado de três em três anos nos países da comunidade europeia e nos países convidados, aplicado por amostragem, em estudantes de 15 anos, tendo como conteúdo de avaliaçáo linguagem, matemática e ciências. No Brasil, o PISA foi implantado em 2000, por meio de um consórcio internacional, e é coordenado pelo Inep que traduz as questóes.

Tal avaliação internacional influenciou preponderantemente na criação do Ideb e no estabelecimento da meta de que o País tenha nota 6,0 em 2022, nota que corresponde aos resultados obtidos pelo PISA nos países membros da OCDE. Para o alcance dessa meta, o Inep/MEC fez uma projeçáo para o Brasil e seus entes federados de 2007 a 2021, vislumbrando um aumento médio de 0,3 pontos a cada ediçáo bianual do Ideb. 


\section{ALGUNS RESULTADOS DO SISTEMA DE AVALIAÇÃO BRASILEIRO}

Analisando as planilhas divulgadas pelo Inep/MEC, com dados de taxas de aprovação, das notas do Saeb e dos resultados do Ideb, de 2005 e 2007, elaboramos tabelas, a fim de tecermos comparações entre os anos selecionados. A tentativa é de extrairmos reflexões que avancem na compreensão dos resultados que o sistema de avaliação brasileiro vem gerando, rumo à superação da leitura pura e simples dos dados divulgados no site oficial do MEC e em propagandas do governo veiculadas na mídia.

Na tabela 1, são apresentadas as taxas de aprovação das etapas: séries iniciais do ensino fundamental, séries finais do ensino fundamental e ensino médio. Foi retirado da planilha o valor total de cada etapa, desconsiderando os valores por série discriminados pelo Inep. A tabela 2 foi elaborada com o objetivo de comparar os resultados de 2005 e 2007, em cada etapa de ensino, e, ainda, em cada esfera de oferta dessas etapas.

Podemos observar que a taxa de aprovação, utilizada para efeito de cálculo no Ideb sofreu, na maioria dos casos, considerável aumento quando se compara $2005 \mathrm{e}$ 2007. Ou seja, o número de reprovaçôes diminuiu, o que garante melhoria no fluxo de alunos da educação básica.

Tabela 1 - Taxa de aprovação em 2005 e 2007

\begin{tabular}{l|c|c|c|c|c|c}
\hline & \multicolumn{3}{|c|}{2005} & \multicolumn{3}{c|}{ 2007 } \\
\cline { 2 - 7 } Total & $\mathbf{S I}$ & SF & EM & SI & SF & EM \\
\hline Pública & 89,4 & 77,0 & 73,2 & 93,0 & 79,8 & 74,1 \\
\hline Privada & 95,1 & 94,5 & 92,7 & 97,3 & 95,1 & 93,8 \\
\hline Municipal & 88,9 & 73,2 & 75,4 & 92,1 & 77,6 & 75,0 \\
\hline Estadual & 91,7 & 76,3 & 70,5 & 94,0 & 78,7 & 71,6 \\
\hline
\end{tabular}

Fonte: Brasil, 2009.

Legenda: SI- Séries iniciais do ensino fundamental. SF- Séries finais do ensino fundamental. EM- Ensino médio. 
Nas séries iniciais do ensino fundamental, em seu valor total, a taxa de aprovação aumentou 3,5 pontos. Foi a etapa que mais cresceu na promoçáo dos alunos, considerando a junção das esferas pública e privada.

Nas séries finais do ensino fundamental, ocorreu o mesmo movimento, pois houve elevação de 2,8 pontos na taxa de aprovação. Entretanto, é na rede pública que se apresenta a maior evoluçáo na promoção dos alunos dessa etapa de ensino.

Já na última etapa da educaçáo básica - o ensino médio - o aumento foi apenas de 0,9 pontos no seu total.

Tabela 2 - Crescimento da taxa de aprovação de 2005 para 2007

\begin{tabular}{l|c|c|c}
\hline & SI & SF & EM \\
\hline Total & 3,5 & 2,8 & 0,9 \\
\hline Pública & 3,1 & 3,2 & 1,2 \\
\hline Privada & 2,2 & 0,6 & 1,1 \\
\hline Municipal & 3,2 & 4,4 & 0,4 \\
\hline Estadual & 2,3 & 2,4 & 1,1 \\
\hline
\end{tabular}

Tais dados evidenciam a afirmação de pesquisadores da área de que o Ciclo Básico de Alfabetização (CBA), implantado no ensino fundamental da maioria das redes de ensino, principalmente nas séries iniciais, possui papel preponderante na diminuiçáo das reprovaçóes, vislumbradas pelos gestores dos sistemas de ensino. Tal premissa está evidenciada nos dados apresentados anteriormente, pois os anos iniciais do ensino fundamental foram os que tiveram maior crescimento na taxa de aprovação.

Além disso, o ensino médio, talvez por não possuir ainda caráter de universalidade, incorre em sérios e históricos problemas estruturais que se deflagram nos dados analisados.

Outro fator utilizado para efeito de cálculo no Ideb sáo as notas obtidas no Saeb. Por isso, a visualização e análise, ao menos preliminares, de seus resultados se faz latente. Considera-se nas tabelas 3 e 4 a média ${ }^{6}$ das notas padronizadas (N) obtidas no exame aplicado pelo Saeb.

${ }^{6} \mathrm{O}$ cálculo da média das notas padronizadas $(\mathrm{N})$ foi feito e divulgado pelo Inep no site oficial. 
Tabela 3 - Média das notas padronizadas do Saeb em 2005 e 2007

\begin{tabular}{l|c|c|c|c|c|c}
\hline & \multicolumn{3}{|c|}{2005} & \multicolumn{3}{c|}{ 2007 } \\
\cline { 2 - 7 } Total & SI & SF & EM & SI & SF & EM \\
\hline Pública & 4,58 & 4,52 & 4,36 & 4,86 & 4,70 & 4,44 \\
\hline Privada & 6,12 & 4,28 & 4,08 & 4,69 & 4,49 & 4,20 \\
\hline Municipal & 4,30 & 4,18 & 3,71 & 4,73 & 4,40 & 4,05 \\
\hline Estadual & 4,55 & 4,32 & 4,06 & 4,85 & 4,53 & 4,18 \\
\hline
\end{tabular}

Fonte: Brasil, 2009.

$\mathrm{Na}$ tabela 3, pode-se observar que as notas obtidas nos exames padronizados ainda estáo longe de ser satisfatórias. Elas variam de 4,05 (rede municipal) a 6,15 (rede privada). Os piores resultados estáo localizados no ensino médio, tanto em 2005 quanto em 2007, e os melhores nas séries iniciais, nas duas ediçóes do Saeb. Vejamos na tabela 4 seus avanços e recuos comparando-se as aplicaçóes de 2005 e 2007.

Tabela 4 - Crescimento da nota média padronizada do Saeb de 2005 para 2007

\begin{tabular}{l|c|c|c}
\hline & SI & SF & EM \\
\hline Total & 0,28 & 0,18 & 0,08 \\
\hline Pública & 2,30 & 0,21 & 0,12 \\
\hline Privada & 0,02 & $-0,01$ & $-0,06$ \\
\hline Municipal & 0,43 & 0,22 & 0,34 \\
\hline Estadual & 0,30 & 0,21 & 0,12 \\
\hline
\end{tabular}

$\mathrm{Na}$ tabela 4, observa-se que houve, em sua maioria, aumento nas médias padronizadas do Saeb se comparadas as ediçóes de 2005 e 2007 . Isso ocorreu principalmente nas séries iniciais da rede municipal de ensino com crescimen- 
to de 0,43 na média. A rede estadual apresentou maior crescimento na média das série finais do ensino fundamental $(0,21)$. Já a rede privada, apesar de obter resultado superior à rede pública nos anos de 2005 e 2007, náo apresentou a mesma tendência de crescimento da rede pública e, ainda, sofreu queda de rendimento nos anos finais do ensino fundamental $(-0,01)$ e no ensino médio $(-0,06)$.

Com relação à rede pública de ensino, é perceptível que a descentralização de responsabilidades entre os entes federados, na qual as séries iniciais ficam prioritariamente sob responsabilidade dos municípios e os anos finais prioritariamente sob responsabilidade dos Estados, tem impacto nos resultados das notas dos exames. Nota-se que tanto a rede municipal quanto a estadual apresentam melhora nos resultados da etapa que prioritariamente vem ofertando em suas redes de ensino.

Nas tabelas 5 e 6 são apresentados os resultados do Ideb e seu crescimento nas edições de 2005 e 2007.

Tabela 5 - Resultados do Ideb em 2005 e 2007

\begin{tabular}{l|c|c|c|c|c|c}
\hline & \multicolumn{3}{|c|}{2005} & \multicolumn{3}{c|}{$\mathbf{2 0 0 7}$} \\
\cline { 2 - 7 } Total & SI & SF & EM & SI & SF & EM \\
\hline Pública & 3,8 & 3,5 & 3,4 & 4,2 & 3,8 & 3,5 \\
\hline Privada & 5,6 & 3,2 & 3,1 & 4,0 & 3,5 & 3,2 \\
\hline Municipal & 3,4 & 3,1 & 2,9 & 4,0 & 3,4 & 3,2 \\
\hline Estadual & 3,9 & 3,3 & 3,0 & 4,3 & 3,6 & 3,2 \\
\hline
\end{tabular}

Fonte: Brasil, 2009.

Na primeira edição do Ideb as médias oscilaram de 2,9 a 4,3 na rede pública de ensino. Já a rede privada vislumbrou melhores índices que variaram de 5,6 a 6,0. Além disso, nas séries iniciais estão as maiores médias, nas ediçóes de 2005 e de 2007 , tanto na rede pública quanto na privada. O ensino médio é a etapa da educação básica com os menores índices, apresentado sensível avanço na rede pública e estagnaçáo na rede privada. 
Diante disso, tornou-se nítida a preocupaçáo dos poderes públicos no sentido de obter melhores resultados na rede pública de ensino. Isto porque estamos apresentando a média nacional, pois se nos detivermos em analisar as médias por escola ou município ${ }^{7}$ encontraremos índices ainda mais baixos, como, por exemplo, 2,3 e 2,9 no município de Bela Vista do Paraíso-PR, na 8a série do ensino fundamental, em 2005 e 2007, respectivamente.

Contudo, nota-se a ausência de destaque, por parte dos poderes públicos, em relacionar os resultados do Ideb com outros fatores que interferem indiretamente no desempenho estudantil, como a taxa de aprovação e o desempenho cognitivo dos alunos. Souza, Gouveia e Tavares (2009) realizaram estudo na região metropolitana de Curitiba, cruzando dados do Ideb, com o Índice de Desenvolvimento Humano (IDH) e com a taxa de pobreza dos municípios que compóem a regiáo. Demonstraram que os municípios mais pobres tendencialmente apresentam menor Ideb, salvo exceçôes.

Tabela 6 - Crescimento do Ideb de 2005 para 2007

\begin{tabular}{l|c|c|c}
\hline & SI & SF & EM \\
\hline Total & 0,4 & 0,3 & 0,1 \\
\hline Pública & 0,4 & 0,3 & 0,1 \\
\hline Privada & 0,1 & 0,0 & 0,0 \\
\hline Municipal & 0,6 & 0,3 & 0,3 \\
\hline Estadual & 0,4 & 0,3 & 0,2 \\
\hline
\end{tabular}

Se considerarmos a projeção do MEC de aumento médio de 0,3 pontos a cada edição bianual do Ideb para o alcance da média 6,0 até 2022 , deflagra-se que a rede pública vem cumprindo a contento a galgada em direção a essa meta, pois nas sé-

7 Para ver os resultados por escola e por município acesse o site <www.inep.gov.br>. O exemplo dado neste texto foi por termos pesquisa desenvolvida na Regiáo Metropolitana de Londrina (RML), em que as informaçōes coletadas indicam que municípios com Índice de Desenvolvimento Humano (IDH) baixo apresentam, em sua maioria, os piores resultados no Ideb. A esse respeito, dados do Nupe/UFPR sáo elucidativos quando cruzam dados do Ideb com a taxa de pobreza e o IDH dos municípios da Regiáo Metropolitana de Curitiba e Litoral do Paraná (RMCL). Os resultados da pesquisa estâo disponíveis em: <www.nupe.ufpr.br>. 
ries iniciais o crescimento foi 0,4 , nas séries finais 0,3 e o ensino médio, ainda náo adaptado a essa projeção, cresceu apenas 0,1 ponto. Por outro lado, a rede privada avançou muito pouco nas séries iniciais $(0,1)$, e nas séries finais do ensino fundamental e no ensino médio o índice não aumentou.

Outro aspecto observado foi que nas etapas em que o índice aumentou de 2005 para 2007, não foram as notas do Saeb que tiveram maior peso e sim a taxa de aprovação que se elevou com maior intensidade, ou seja, o índice melhorou não porque os alunos estão apreendendo mais os conteúdos, mas porque estão sendo aprovados em maior número.

Esses resultados representam que apenas a taxa de aprovaçáo e o desempenho cognitivo do alunado estão refletidos nesses índices, e que se fossem considerados outros determinantes, já destacados anteriormente, talvez tais resultados trouxessem elucidaçōes mais amplas e complexas da medição da qualidade do ensino brasileiro. Entretanto, tais resultados podem propiciar reflexóes importantes quanto aos desdobramentos do sistema de avaliaçấo nas redes de ensino pública e privada.

Todavia, apesar das limitaçôes apresentadas acerca do sistema de avaliaçáo brasileiro, visualizam-se sentidas mudanças nas médias obtidas nas notas padronizadas no Saeb, e, principalmente, nas taxas de aprovação, o que consequentemente tem melhorado os resultados do Ideb. Cabe compreender, em pesquisas posteriores, como as unidades escolares e as redes de ensino vêm se esforçando para atingirem as metas definidas nacionalmente.

\section{CONSIDERAÇÕES FINAIS}

O estudo acerca do sistema de avaliação no Brasil precisa ser ampliado para que a divulgação de seus resultados, tão disseminados atualmente, não seja assimilada alienadamente, ou seja, desconsiderando a amplitude e totalidade de aspectos inerentes, direta ou indiretamente, à medição da qualidade do ensino. Quanto à última, existe eminente esforço dos pesquisadores e profissionais da área da educaçáo em explicitar a sua significância eivada na necessária superaçáo de conceituaçôes e mecanismos simplistas que historicamente não têm demonstrado estratégias satisfatórias que engendrem a garantia constitucional ao direito à educaçáo de qualidade a todos os cidadáos.

Se compararmos linearmente os objetivos e metas proclamados nos documentos oficiais quanto ao papel vital do sistema nacional de avaliaçáo de avaliar a qualidade do ensino, objetivando estimular a melhoria dos padróes de qualidade e promover a equidade da educação brasileira, aos resultados produzidos e disseminados pelo Inep/MEC, podemos afirmar que tais metas vêm sendo percorridas 
com aparentes avanços, em razão de sua constante evoluçáo nos anos analisados. Entretanto, se considerarmos os mecanismos de gestão que vêm sendo empreendidos como desdobramento dos resultados produzidos pelo sistema nacional de avaliação, nota-se a opção por um caminho de não-superação de um viés classificatório e competitivo entre as escolas e redes de ensino. Para se atingir a qualidade de ensino, intencionada nos documentos oficiais analisados, para além do alcance de metas, seriam necessárias, entre outras açóes, a utilizaçáo dos indicadores socioeconômicos e contextuais no desenho do perfil do aluno, do perfil da gestão e do perfil do professor, para, frente a isso, gerar políticas educacionais consistentes, com uma gestão pautada no regime de colaboração entre os entes federados, com política de formação e valorização do magistério, com educação em tempo integral, investimento em educação similar aos países da OCDE (7\% do PIB aproximadamente), entre outros aspectos fundamentais no provimento da melhoria da qualidade do ensino público.

Nota-se um fosso entre os objetivos proclamados nos documentos oficiais, salvaguardando qualidade, igualdade e equidade, e os mecanismos de gestão e financiamento dos sistemas de ensino, que percorrem solitária, indistinta e alienadamente o alcance de metas que não refletem em sua plenitude o real nível de qualidade da educação brasileira.

Ademais, se considerarmos que os resultados de desempenho estudantil disseminados pelo Inep/MEC podem ser suscetíveis a conjecturas, inferimos que os dados compilados denunciam que ainda há muito a avançar na superação da disparidade nos resultados de desempenho estudantil entre os sistemas de ensino dos entes federados - estaduais e municipais - e na estagnação dos resultados obtidos no ensino médio. Quanto ao primeiro, podemos sugerir que, no mínimo, o desenho de colaboração entre os entes federados por meio do PAR e demais convênios, precisa ser aprimorado de forma a nivelar por cima as desigualdades deflagradas nos dados compilados.

É possível, então, detectar, no contexto atual, que os resultados do sistema nacional de avaliação têm direcionado políticas educacionais estaduais e municipais a gerirem seus sistemas de ensino pautados na responsabilização individual dos alunos, dos professores e das escolas pelo seu baixo ou alto desempenho, desencadeando mecanismos de premiação diante dos resultados obtidos. Por exemplo, o Estado de São Paulo possui gestão de ensino pautada na premiação. De acordo com o jornal O Globo (2/7/2009 e 19/7/2009) os Estados do Rio de Janeiro e do Ceará também incorporaram, em sua gestão pública de ensino, mecanismo de bonificação 
ao professor e à escola, vinculado ao resultado do desempenho estudantil em exames padronizados. O jornal Gazeta-ES publicou em 29/10/2009 a aprovação, no Estado do Espírito Santo, de projeto de lei que adere a esse modelo de gestão. Tal modelo de gestão pode gerar uma intensificação na diversificação da qualidade do ensino público, dificultando a garantia constitucional de estabelecimento de padráo de qualidade educacional a todos os cidadáos brasileiros.

Com isso, o sistema de avaliação instalado no atual contexto carece de amplo debate para desvelar impasses e superar equívocos presentes no uso que se tem feito dos resultados do Saeb e do Ideb disseminados pelo Inep, ato que tende a supervalorizar o desempenho estudantil e do professorado e obscurecer e/ou desconsiderar outros determinantes de igual ou maior relevância na mensuraçáo da qualidade do ensino.

Portanto, não podemos deixar de considerar e analisar as informaçóes relevantes acerca do desempenho estudantil e do contexto intra e extraescolares que o sistema de avaliação nos fornece. Isso porque, a análise e utilização de tais informaçóes devem servir como norteadores no aprimoramento das políticas educacionais rumo a universalização da qualidade do ensino enquanto direito subjetivo dos cidadáos.

\section{REFERÊNCIAS BIBLIOGRÁFICAS}

ALVES, Thiago; PASSADOR, Cláudia S.; NORONHA, Adriana B. A Relação entre desempenho escolar, condições de oferta de ensino e origem socioeconômica em escolas da rede pública de ensino. In: Simpósio Brasileiro, 23; Congresso Luso-Brasileiro, 5; Colóquio Ibero-Americano de Política e Administração da Educação, 1. 2007, Porto Alegre. Anais... Porto Alegre: ANPAE, 2007.

ARAÚJO, Gilda C. de; FERNANDES, Caroline F. R. Qualidade do ensino e avaliações em larga escala no Brasil: os desafios do processo e do sucesso educativo na garantia do direito à educação. Revista lberoamericana de Evaluación Educativa, $v$. 12, n. 2, 2009.

BONAMINO, Alicia; FRANCO, Creso. Avaliação e política educacional: o processo de instituicionalização do Saeb. Cadernos de Pesquisa, São Paulo, n. 108, p. 101-132, nov. 1999. BONAMINO, Alicia; FRANCO, Creso; ALVES, Fátima.
Qualidade do ensino fundamental: políticas, suas possibilidades, seus limites. Educação \& Sociedade, Campinas, v. 28, n. 100, p. 989-1014, out. 2007. Disponivel em: $<w w w . c e d e s . u n i c a m p . b r>$. Acesso em: jul. 2009.

BRASIL. Ministério da Educação. Planilhas para download. Brasília: MEC/Inep, 2009. Disponivel em: <http://portalideb.inep.gov.br>. Acesso em: fev. 2010.

. Decreto-Lei n. 6.094, de 24 de abril de 2007. Plano de Metas Compromisso Todos pela Educação. Disponível em: <www. planalto.gov.br/ccivil_03/_Ato2007-2010/2007/ Decreto/D6094>. Acesso em: nov. 2009.

. Portaria n. 931, de março de 2005. Institui o Sistema Nacional de Avaliação da Educação Básica. Disponivel em: <www.inep.gov. br/download/saeb/2005/portarias/Portaria931_ NovoSaeb.pdf>. Acesso em: 12 fev. 2010. 
CASASSUS, Juan. Uma nota crítica sobre a avaliação estandartizada: a perda da qualidade e a segmentação social. Sísifo: Revista de Ciências da Educação, p. 71-79, 2009. Disponível em: <www.sisifo.fpce.ul.pt>. Acesso em: nov. 2009.

FERNADES, Reynaldo. Indice de Desenvolvimento daEducação Básica (Ideb). Brasília: MEC/Inep, 2007. LOCATELLI, Iza. Construção de instrumentos para a avaliação de larga escala e indicadores de rendimento: o modelo Saeb. Estudos em Avaliação
Educacional, São Paulo, n. 25, jan./jun. 2002. SOARES, José F.; ANDRADE, Renato J. de. Nível socioeconômico, qualidade e equidade das escolas de Belo Horizonte. Ensaio: Avaliação, Políticas Públicas e Educação. Rio de Janeiro, v. 14, n. 50, p. 107-126, jan./mar. 2006.

SOUZA, Ângelo R. de; GOUVEIA, Andréa B.; TAVARES, Taís $M$. O Ideb e as políticas educacionais na região metropolitana de Curitiba. Estudos em Avaliação Educacional, São Paulo, v. 20, n. 42, p. 45-58, 2009. 